\title{
Numerical and experimental analysis for simulating fuel reactor in chemical looping combustor system
}

\author{
Tamer M. Ismail ${ }^{1} \cdot$ Lu Ding $^{2} \cdot$ Khaled Ramzy $^{1} \cdot$ M. Abd El-Salam ${ }^{3}$
}

Received: 25 January 2020/Revised: 21 April 2020/Accepted: 8 July 2020/Published online: 21 July 2020

(C) The Author(s) 2020

\begin{abstract}
The greenhouse problem has a significant effect on our communities such as, health and climate. Carbon dioxide is one of the main gases that cause global warming. Therefore, $\mathrm{CO}_{2}$ capture techniques have been the focus of attention these days. The chemical looping combustion technique adopted the air reactor and fuel reactor to recycle heat energy. This study presents a numerical and experimental investigation on a fuel reactor in chemical looping combustor (CLC) system. The present numerical model is introduced by the kinetic theory of granular flow and coupled with gas-solid flow with chemical reactions to simulate the combustion of solids in the CLC. The $k-\varepsilon$ turbulent model was used to model the gas phase and the particle phase. The developed model simplify the prediction of flow patterns, particle velocities, gas velocities, and composition profiles of gas products and the distribution of heterogeneous reaction rates under the same operating conditions. The predicted and experimental results were compared according to the basis of determination coefficient $\left(R^{2}\right)$. In addition the results showed that there is a good agreement between the predicted and experimental data. The value of $\left(R^{2}\right)$ for $\mathrm{CO}, \mathrm{CO}_{2}$ and $\mathrm{CH}_{4}$ was $0.959,0.925$ and 0.969 respectively. This shows that the present model is a promising simulation for solid particle combustion and gives the power direction for the design and optimization of the CLC systems.
\end{abstract}

Keywords Chemical looping combustion $\cdot$ Mathematical modeling $\cdot$ Fluidized bed $\cdot$ Coal $\cdot$ Kinetic model

Electronic supplementary material The online version of this article (https://doi.org/10.1007/s40789-020-00351-y) contains supplementary material, which is available to authorized users.

Tamer M. Ismail

temoil@aucegypt.edu; tamer.ismail@eng.suez.edu.eg

$\triangle$ Khaled Ramzy

kh.ramzy2005@yahoo.com;

kh.ramzy2005@eng.suez.edu.eg

1 Department of Mechanical Engineering, Suez Canal University, Ismailia, Egypt

2 Institute of Clean Coal Technology, East China University of Science and Technology, Shanghai 200237, China

3 Department of Basic Science, Cairo University, Giza, Egypt

\section{Introduction}

The greenhouse effect has been the focus of attention of many scientists recently. Carbon dioxide is treated as the greenhouse gas; the formation of carbon dioxide as a result of the combustion of fossil fuels is considered as a contributing to an increase the global warming temperature. Therefore, future exploitation of fossil fuels will obligate carbon management to achieve power generation without an increase in greenhouse gases. Interestingly, in trying to reduce fossil fuel consumption and reduce costs, efforts are underway to greatly increase energy efficiency and use energy in a smarter way. Given the absence of credible alternative sources, the use of fossil fuels is still essential.

Therefore, new ways must be developed to reduce the emissions of $\mathrm{CO}_{2}$ from the fossil fuels combustion. Due to the threat of global warming, research has focused on technology development to produce energy without 
releasing greenhouse gases like $\mathrm{CO}_{2}$. Multiple kinds of technology are currently being developed for $\mathrm{CO}_{2}$ capture, including oxyfuel combustion, post-combustion capture from flue gases, and carbon shift (Simbeck 2004). Although these methods consume a great deal of energy and thus can lead to a considerable increase in the cost of electricity consumption, they are nevertheless being developed to separate gases. Power generation through a CLC supplies a sequestration-ready $\mathrm{CO}_{2}$ stream and helps to avoid various costly and energy-consuming techniques of gas separation such as absorption (MEA, Selexol), adsorption (PSA, TSA), membranes, or cryogenics, among others. Therefore, a CLC can be responsible for heterogeneous chemical reactions with an oxygen carrier due to involve the combustion of fuels and a granular metal oxide, which are exchanged between the two fluidized bed reactors (Johansson et al. 2004; Kolbitsch et al. 2009). As a result, the $\mathrm{CO}_{2}$ can be inherently separated in this combustion process. Also the total amount of heat released in the air and the fuel reactor is equal to the heat released from normal combustion process, therefore separating $\mathrm{CO}_{2}$ without any loss in energy (Adanez et al. 2005; Mattisson et al. 2004; Dennis et al. 2006; Leion et al. 2007; Scott et al. 2006). Most work on chemical looping combustion has focused on the use of gaseous fuel, with only a few researches concerned with solid fuel. However, coal is considerably more abundant than natural gas, so it would be highly advantageous if the solid fuels adapted and used in the CLC system. There are many and different experimental and numerical researches were performed on the CLC technology. Lyngfelt et al. (2001) presented the first chemical looping combustion design based on the circulating fluidized bed principle. They recognized the concept of the CLC as a possible system to capture $\mathrm{CO}_{2}$ from fossil fuels in order to decrease climate impact. Scientists such as lyngfelt accomplished more than $4000 \mathrm{~h}$ in 12 units of 0.3-140 kW until the first of 2011 (Lyngfelt 2011). This time of operation consists mostly of operation with gaseous fuels, as they were the first to be tested. During the last few years, more focus has been put on solid and, most recently, liquid fuels. However, liquid fuels have been tested by some scientists such as Hoteit et al. and Moldenhauer et al. in relatively small lab units (Hoteit et al. 2011; Moldenhauer et al. 2012).

Kronberger et al. (2005) designed a CLC prototype of $10 \mathrm{~kW}$ with a dual-fluidized bed reactor system. They measured the solids circulation rate, static pressure balance and residence time distribution of gas and particles. They noticed that the rates of solid circulation were sufficient and the gas leakage can be controlled at very low level. Markström et al. (2014) introduced the design and operation of a $100 \mathrm{~kW}$ chemical-looping combustor for solid fuels. They used a Mexican petroleum coke and a bituminous coal as a fuel. They concluded that gas concentration measurements showed the presence of unconverted $\mathrm{CO}, \mathrm{H}_{2}$ and $\mathrm{CH}_{4}$ corresponding to an oxygen demand of around $20 \%$, depending on the fuel reactor temperature. Linderholm et al. (2017) used a sintered manganese ore as oxygen carrier during the combustion of solid fuel in a $100 \mathrm{~kW}$ chemical-looping combustion unit. They found that the expected lifetime of the oxygen carrier was about $100-400 \mathrm{~h}$ depending on the operating conditions. Ma et al. (2018) constructed and operated a $50 \mathrm{~kW}$ chemical looping combustion reactor for coal. They performed a series of tests to investigate the performance of the newly constructed CLC reactor under different operational parameters such as temperature, inlet gas velocity and $\mathrm{H}_{2} \mathrm{O}$ concentration in fluidizing agent. The results showed that the highest combustion efficiency of 0.86 was achieved at $1000{ }^{\circ} \mathrm{C}$. Abanades et al. (2020) introduced a novel air reactor concept for chemical looping combustion systems operated at high pressure. Their results showed that the novel reactor can generate $100 \mathrm{MW}$ and the reactor can be particularly useful for back-up power services operating intermittently for more than $9 \mathrm{~h}$. The carrier (metal oxide) supplies the oxygen for the reaction in CLC which leads to an easy separation of $\mathrm{CO}_{2}$. The flue gas stream obtained from the reaction in the CLC has a considerable amount of carbon dioxide and steam. Thus, condensing the steam directly will create pure $\mathrm{CO}_{2}$ that can be easily sequestrated (Hossain and de Lasa 2008; Deng et al. 2009). Ferric oxide $\left(\mathrm{Fe}_{2} \mathrm{O}_{3}\right)$, Copper oxide $(\mathrm{CuO})$, Nickel oxide $(\mathrm{NiO})$, and Manganese oxide $\left(\mathrm{Mn}_{3} \mathrm{O}_{4}\right)$ are the main metal oxides of the oxygen carriers. The inert material is considered as a metal support which can supply a higher surface area for the reactions. It can also be treated as a binder to increase the attrition resistance and mechanical strength (Abad et al. 2007). Different research, with varying models, has focused on the fluidized bed performance with regards to computational fluid dynamics. Wang et al. simulated the bubbling fluidized bed, while Chen et al. used the Eulerian-Eulerian model, incorporating the kinetic theory of granular flow to investigate gassolid flow in fluidized beds (Wang et al. 2009; Chen et al. 2011). Due to the high cost of the experimental work and limitations of the measurement, few studies were performed on CLC. Jung and Gamwo simulated and modelled the $\mathrm{CLC}$ with using $\mathrm{NiO}$ and $\mathrm{CaSO}_{4}$ as respective oxygen carriers (Jung and Gamwo 2008). Several numerical studies have described the reduction and oxidation manner in oxygen carriers (Lu et al. 2003; Abad et al. 2007; Jung and Gamwo 2008; Wang et al. 2009; Chen et al. 2011; Su et al. 2015; Deng et al. 2009). Regarding this issue, the solid combustion in CLC was simulated as a result of developing the mathematical modeling. Also the modelling were performed on the fuel reactor for different gases with different 
oxygen carriers such as Parker (2014), Han and Bollas (2016), Porrazzo et al. (2016), Menon and Patnaikuni (2017), Zhang et al. (2017), Haus et al. (2018) and Hamidouche et al. (2019).

The present work considers the flow of gases and solids as well as homogenous and heterogeneous chemical reactions. The experimental work in this field is very hard, difficult, complicated, and thus too expensive to be employed. The $k-\varepsilon$ turbulent model and the kinetic theory of granular flow were used in gases modeling and the particle phase, respectively. The rate of heterogeneous reactions is presented using dissipation and diffusion rates. The model can be validated by comparing the experimental results to those obtained from the present code. In this model, the kinetic theory of granular flow (KTGF) and EMMS/Matrix correction was integrated to simulate the gas-solid flow hydrodynamics in the fluidized bed, coupled with a sub-models for the chemical reaction and heat transfer. The distribution of simulated temperature, voidage and gas composition from the furnace outlet were modeled also.

\section{Experimental work}

Taking into account the abilities and conditions of Suez Canal University in Egypt, the experimental work was achieved according to the description as shown in Fig. 1. The system includes designing a $2.5 \mathrm{~m}$ tall air reactor (velocity fluidized bed) with a $0.15 \mathrm{~m}$ inner diameter. The experimental work consists of air reactor, fuel reactor, air entrance which is connected with the air compressor, metal powder entrance and cyclone which is a very important conical part of the CLC system. It has two functions: the first one is to collect the oxygen carrier particles and directs them to the fuel reactor. The second one is to exhaust the air containing the nitrogen gas. Thus, the combustion exhaust product does not contain harmful $\mathrm{NO}_{x}$. In addition the experimental work contains butterfly valves to control the flow rate, gas source and the chimney that designed to allow the emission gases to go out of the system without backpressure. Particle recirculation between the fuel reactors and the air was implemented as the cyclone captured the particles passing through the riser and returned them to the fuel reactor (bubbling fluidized bed reactor). The fuel reactor was designed as a fluidized bed with an inner diameter of $0.3 \mathrm{~m}$ and a height of $0.95 \mathrm{~m}$. The system was supported with eight K-type thermocouples, distributed at equal distances along the fuel reactor, and six pressure sensors mounted at different elevations along the riser to extract as much processed experimental data as possible. The Orsat gas analyzer apparatus was used to measure emissions from the fuel reactor. The experimental uncertainty analysis was done and evaluated according to Holman (Holman 1994) and Ismail et al. (Ismail et al. 2018). The minimum experimental error is equal to the ratio between its least count and the minimum recorded value of the measured output. The values are small compared to the obtained data and found to be within the allowable range of the measurements. The uncertainty analysis of the K-type thermocouples and pressure sensors were $0.05 \%$ and $0.25 \%$, respectively.

\section{Mathematical modeling of the fuel reactor}

At present, the simulation of solid waste combustion in fluidized bed has been developed by using code, namely COMMENT-Code (Combustion Mathematics and Energy transfer). The simulation uses less advanced technology to study the combustion process of gas phase and solid phase, the concentration and temperature distribution of matter, thus greatly saving the calculation requirements. Through the comparison with the experimental work, the developed code in the current research is verified. The transport equation mathematical model is built based on the conservation of a coupled transport equation and the equation of state of the fluid system. In addition, since most of the actual flows are turbulent, these conservation equations ought to treated as temporal averaging or spatial filtering, and need to be closed by using extra turbulence models. The fluid dispersion in packed beds is investigated to consist of diffusion and turbulence (Peters et al. 2003), more details for the current model description are found in the Supplementary materials. The coal compositions were found based on the proximate analysis and elemental analysis, as shown in Table S2. The method of finite volume (Patankar 1980) was used to solve equations to obtain gas velocity, temperature (or specific enthalpy), and concentration. In this algorithm, the coupling terms were implicitly treated, forming a part of the above mentioned solution substrate. Pressure-velocity coupling was based on the total volume continuity, and the results of the interracial coupling terms were fully integrated into the pressure correction equation. In order to obtain a time- and grid-independent solution, all the presented simulations were carried out with a time step of $2 \times 10^{-3}$ s and a space step of $0.1 \mathrm{~mm}$. The initial conditions were as follows. The combustion process was launched by the gas burner. Thus, in the bed surface, the gas and solid temperatures were set respectively at $1173 \mathrm{~K}$ (the gas combustor ignition temperature), where the temperature lasted for two seconds. The temperature was $300 \mathrm{~K}$ in other areas. The values of mass fractions for $\mathrm{O}_{2}$ and $\mathrm{N}_{2}$ were between $23.3 \%$ and $76.7 \%$, respectively. The fuel reactor has been simulated for the given conditions to analyze and observe the reaction 


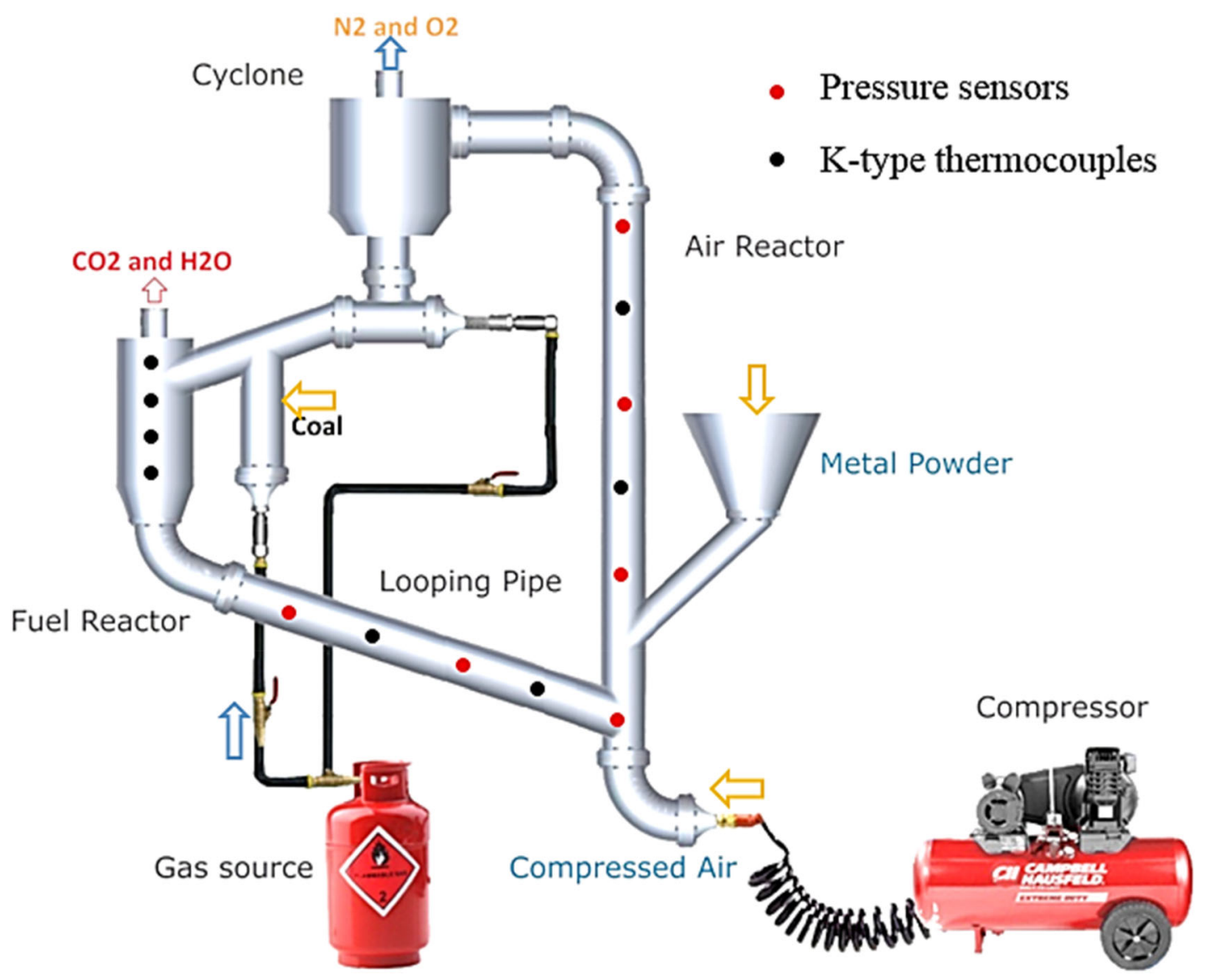

Fig. 1 Schematic diagram of chemical looping combustion

rates, conversion of coal and the overall performance of the system at various operating conditions. The numerical parameters used in the simulation are summarized as in Table 1.

For the independence grid, a comparison result was made between the results of gas concentration for the coarse grid and the fine grid simulation. The maximum difference between the results from the superficial velocity of $0.32 \mathrm{~m} / \mathrm{s}$ was less than $4 \%$. For this reason, fine grids are sufficient for use in all of the simulations presented in this study. Regarding boundary conditions, the above mentioned operating conditions of the gas phase occur/exist at

Table 1 Numerical parameters used in the present model

\begin{tabular}{ll}
\hline Scheme & $\begin{array}{l}\text { Numerical } \\
\text { parameter used }\end{array}$ \\
\hline $\begin{array}{l}\text { Spatial discretization scheme for the momentum } \\
\text { equations and species equation }\end{array}$ & $\begin{array}{l}\text { Second order } \\
\text { upwind } \\
\text { Spatial discretization scheme for each phase }\end{array}$ \\
$\begin{array}{c}\text { Second order } \\
\text { upwind }\end{array}$ \\
Time Integration Scheme & First order \\
& implicit \\
\hline
\end{tabular}

the bottom of the bed, and are respectively given the air temperature and velocity.

\section{Results and validations}

The experimental recorded data were used to validate and find good agreement with the model.

In the chemical looping combustion, oxygen-carrier particles are run between two reactors as shown in Fig. 1. After preparing CLC reactor along the fuel reactor using volume flow rate less than the stoichiometric was measured and recorded. Then the metal powder is transported through a ring seal, to the second reactor where the fuel is inserted, and this reactor is called the fuel-reactor. The fuel and the available oxygen in the oxygen-carrier particles react according to Eq. (1).

$$
\begin{aligned}
(2 n+m) \mathrm{Me}_{x} \mathrm{O}_{y+1}+\mathrm{C}_{n} \mathrm{H}_{2 m} \rightarrow & (2 n+m) \mathrm{Me}_{x} \mathrm{O}_{y}+n \mathrm{CO}_{2} \\
& +m \mathrm{H}_{2} \mathrm{O}
\end{aligned}
$$


Oxygen-carrier becomes reduced in fuel reactor, and the metal powder is transferred to the air reactor to be oxidized as shown in Eq. (2).

$2 \mathrm{Me}_{x} \mathrm{O}_{y}+\mathrm{O}_{2} \rightarrow 2 \mathrm{Me}_{x} \mathrm{O}_{y+1}$

where $\mathrm{Me}_{x} \mathrm{O}_{y+1}$ is oxidized metal-powder and $\mathrm{Me}_{x} \mathrm{O}_{y}$ is reduced metal powder.

Figure 2 presents a variety of average gas concentration changes over time in the outlet. In the first phase, the mole fraction of the gas component remains constant, which is the same as the inlet gas concentration. The duration of this stage depends on the height of the reactor and the inlet gas velocity. In the second phase, the concentration of gaseous reactants rapidly decreases linearly and reverses to achieve the product gas. In the third stage, the gas concentration slightly swings around the fixed value. It was found that the oscillation of freeboard in gas composition was not as intense as that in the densest areas, due to the absence of the solid reactant. According to this operating condition, conversion to $\mathrm{H}_{2}$ was almost completed, due to the high reactivity and low inlet concentration compared with $\mathrm{CO}$.

A comparison between this theoretical model and the experimental work was carried out according to the gas concentration at the outlet of the fuel reactor. Simulated boundary conditions must commit to the experimental work's operating parameters. The experimental work and the predicted data were well-matched at a satisfactory percentage. According to the basis of determination coefficient, the value of $\left(R^{2}\right)$ for $\mathrm{CO}, \mathrm{CO}_{2}$ and $\mathrm{CH}_{4}$ was 0.959, 0.925 and 0.969 respectively. The results of these experiments were consistent with the gas species, meaning that the $2 \mathrm{D}$ numerical simulation is reasonable, as the validity of this model was tested and verified. In order to know the power of the obtained results, it should be validate with other published data such as Menon and Patnaikuni (2017). From results it can be concluded that all curves have the same trend according to their published data.

\section{CFD results and discussion}

For the operating conditions listed in Table S3, the time series of the flow mode calculated in the form of solid volume fraction is shown in Fig. 3 at a time of 100 s. A typical turbulent fluidization model was observed in the lower region of the fuel reactor. Particles accumulate near the wall until they become heavy enough and cannot be carried by gas, forming a core-ring flow structure with a diluted ascending core and a dense downward ring. It is also observed that the gas moves downward near the wall area, showing the strong influence of the downward solid. In most regions of the fuel reactor, the maximum axial velocity is detected in the core for solids and gases. At the exit, higher gas and solid velocities appear on the right, which shows the effect of the outlet geometry. In general, these diagrams show that the model can predict almost symmetric flow patterns in the shell, despite the asymmetric geometry of the inlet and exit.

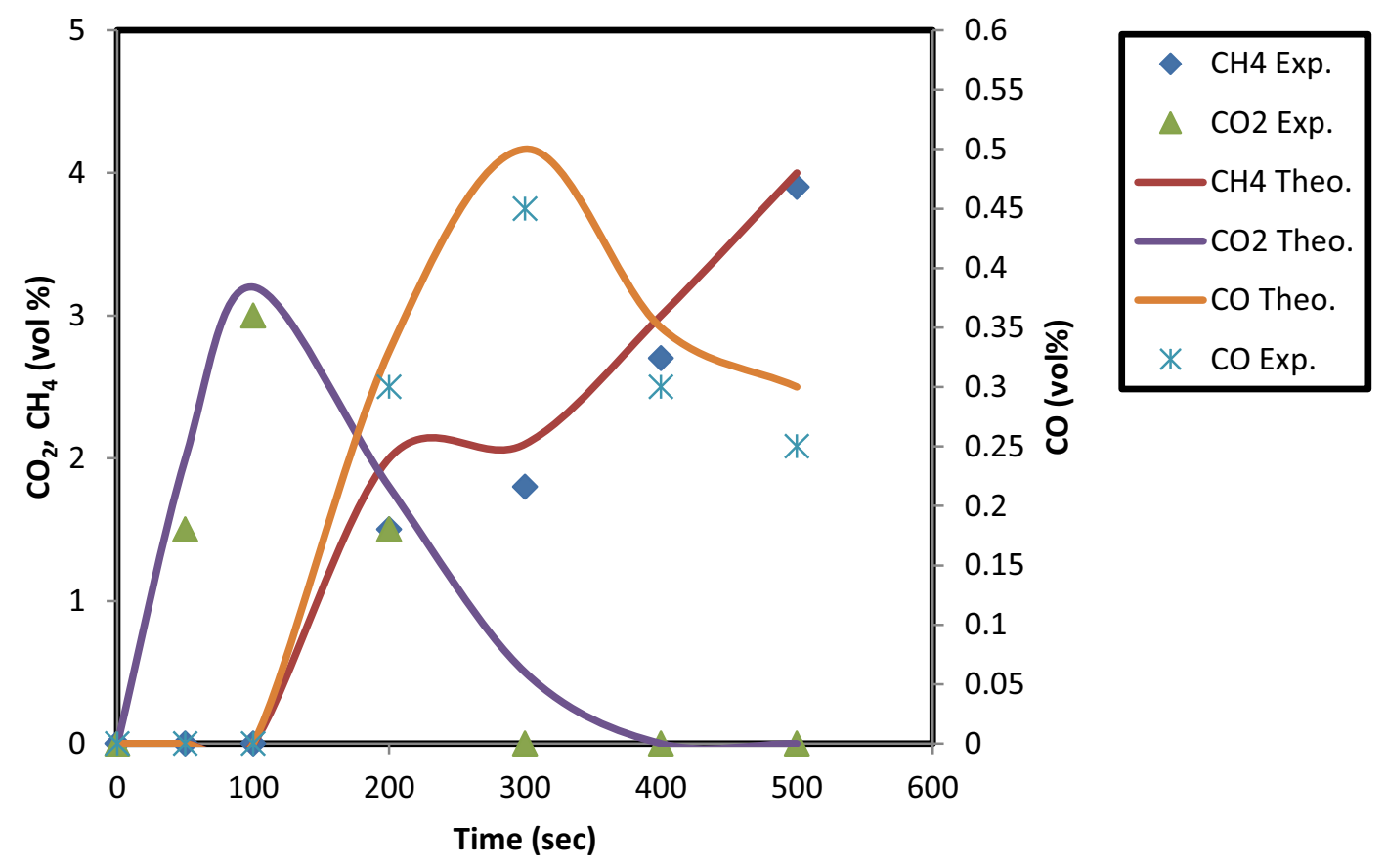

Fig. 2 Comparison between experimental and theoretical species for reduction (fuel) reactor at the quasi-equilibrium state 
Figure 4 shows the profiles of gas temperature and gas species in the fuel reactor. The maximum temperature from the present model was around $1200 \mathrm{~K}$; the peak temperature was observed in the combustion zones, where the highest intensities of oxidation and reduction reaction are located. The gas velocity displayed the same trend, as shown, possibly because temperature is a measure of heat energy that causes the kinetic energy to be produced. Thus, when the temperature increases, the kinetic energy and motion of the molecules also increases. In addition the kinetic energy and motion of the molecules were closely related in this study.

It can be concluded from these contours that the overall trend of each composition profile is consistent. Near the biomass inlet and at the top of the reactor, $\mathrm{CO}$ concentration is high due to the presence of a large number of carbon particles as well as devolatilization. The contours also show that the concentration trend of $\mathrm{H}_{2}$ and $\mathrm{CO}_{2}$ follow each other closely. After some time, the concentration of $\mathrm{CO}$ is decreased because of the lower $\mathrm{O}_{2}$ feed rate (oxidation reaction) and a strong forward water-gas shift reaction that converts all $\mathrm{CO}$ to $\mathrm{CO}_{2}$. On the other hand, a small amount of methane, $\mathrm{CH}_{4}$, is produced, due to the slow methanation reaction rate within the reactor. Low concentrations of $\mathrm{N}_{2}$ correspondingly appear near the coal feeding point.

Due to the devolatilization, the volatiles $\left(\mathrm{CH}_{4}, \mathrm{CO}\right.$, $\mathrm{H}_{2} \mathrm{O}, \mathrm{H}_{2}$, and tar) appear near the coal feeding point with high concentrations; these concentrations are then gradually reduced due to the combustion reaction. In the previously mentioned chemical reaction model, the predicted concentrations of tar are higher than other volatile matters. The carbon dioxide is observed in the dense zone with a certain amount because it is mainly produced by coal combustion. However, due to dry coal devolatilization, $\mathrm{CH}_{4}$ combustion and vaporization contribute a little value. Also, volatile matter observed with large amounts of at the bottom of the dilution region.
Figure 5 shows the conversion of copper carbonate dolomite as a function of time at different bed heights. The trends of conversion are consistent with another carbonation study, which analyzed operating conditions (Gallucci et al. 2008; Stendardo and Foscolo 2009). The solid and gas phase in the fluidized bed were simulated at $873 \mathrm{~K}$, as was the gas entering the reactor. Due to the small particle diameter $(103 \mu \mathrm{m})$ and the intrinsic bed fluidization, we can consider the solid phase isotherm. The $\mathrm{CO}_{2}$ in the gas phase reacts with $\mathrm{CuO}$ to produce $\mathrm{CuCO}_{3}$ in the solid phase. The maximum conversion which copper carbonate can achieve is a function of the composition.

Another important aim of this study is the application of a grain model in a fluidized environment. In order to evaluate this model, the solid conversion of copper carbonate dolomite was studied as a function of time. The carbonation reaction in the chemical looping combustor (fuel reactor) exists in three stages. In the first, the chemical kinetics were the limiting reaction, whereas in the third, the diffusion through the particle was the controlling step and the reaction rate decreased strongly. Between these two stages was a transition zone, named the breakthrough period, which was found where both surface reaction and diffusion resistance were the controlling mechanisms of the whole $\mathrm{CO}_{2}$ capture process.

\section{Conclusions}

The capture and separation of carbon dioxide from the combustion of fossil fuel may become a new alternative solution to minimize the effect of greenhouse gases. $\mathrm{CO}_{2}$ captured after the condensation process can be stored in tanks to be used economically in many industrial applications. As a result, a coal-fired power plant will store pure $\mathrm{CO}_{2}$ in tanks, instead of releasing flue gases out of chimneys into the atmosphere, and this stored $\mathrm{CO}_{2}$ can be sold to those concerned with the industrial applications of $\mathrm{CO}_{2}$.
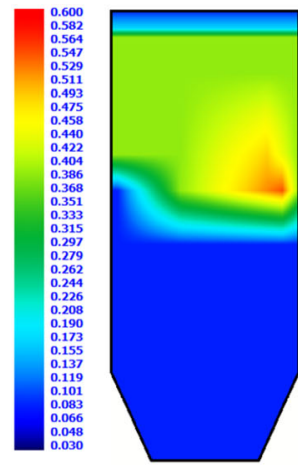

$1 \mathrm{sec}$

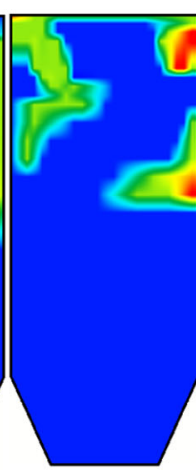

$10 \mathrm{sec}$

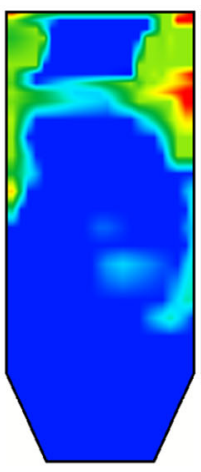

$20 \mathrm{sec}$

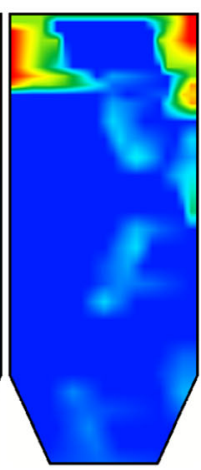

$40 \mathrm{sec}$

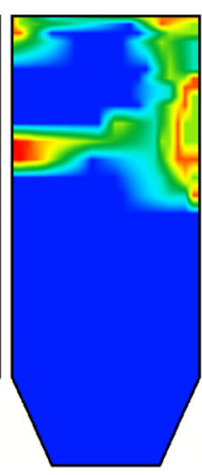

$60 \mathrm{sec}$

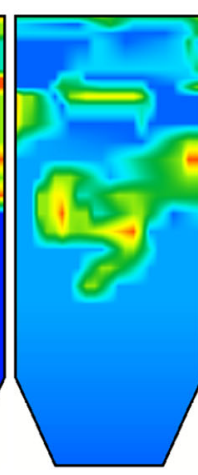

$80 \mathrm{sec}$

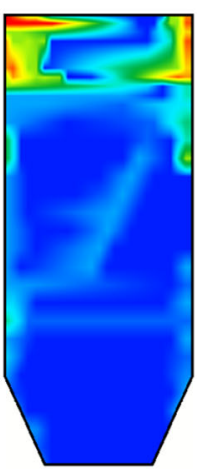

$100 \mathrm{sec}$

Fig. 3 Simulated results of solid volume fraction as function in time for the gas-particle flow in the upper part of the fuel reactor 


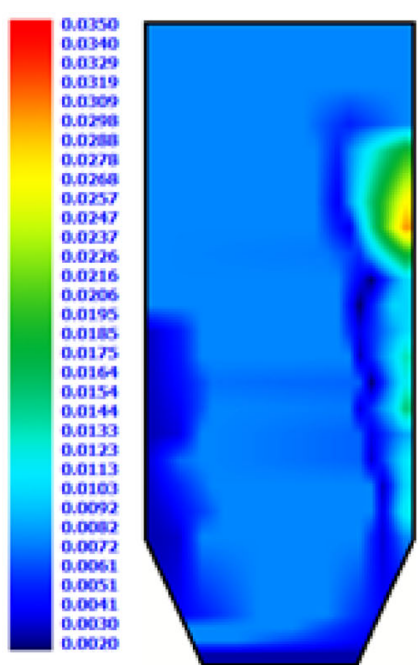

$\mathrm{CH}_{4}$
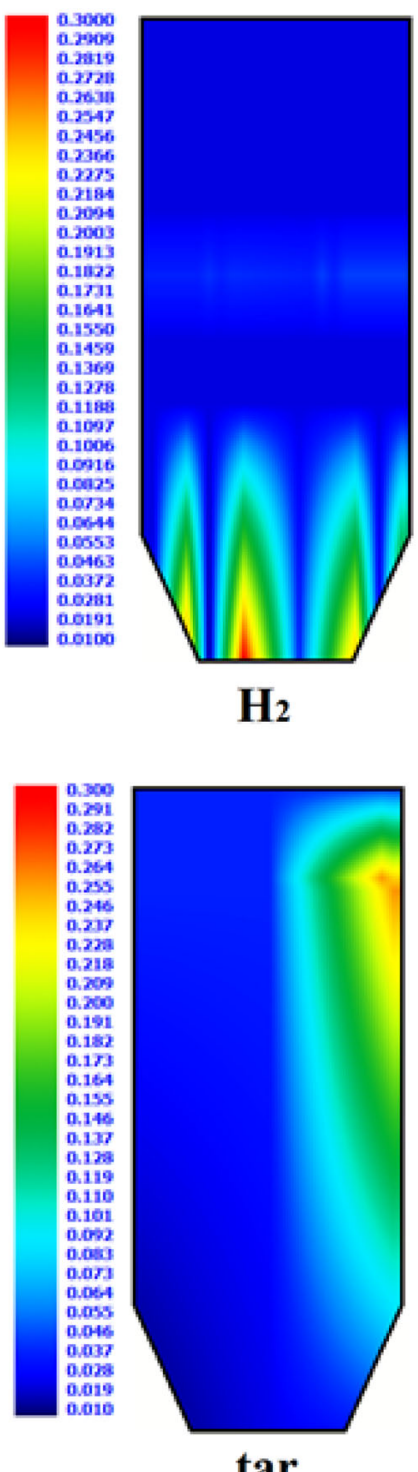
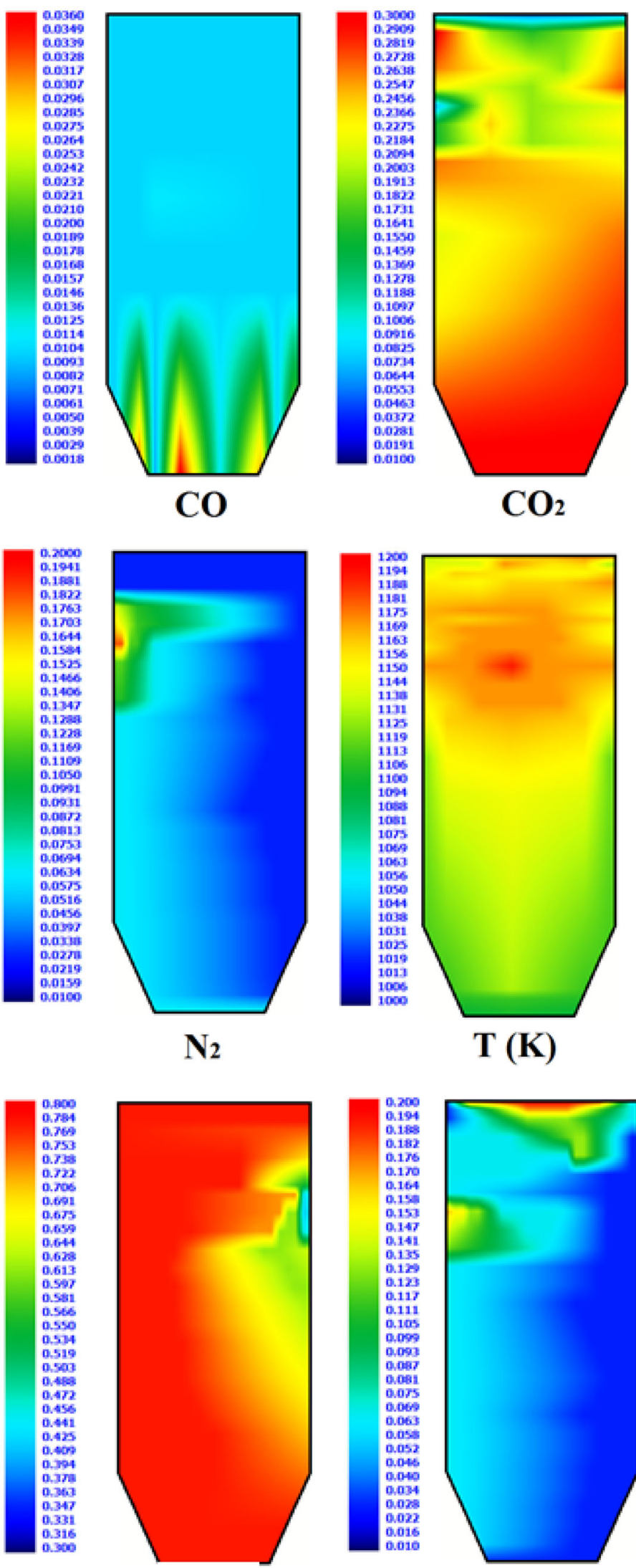

$\mathrm{H}_{2} \mathrm{O}$

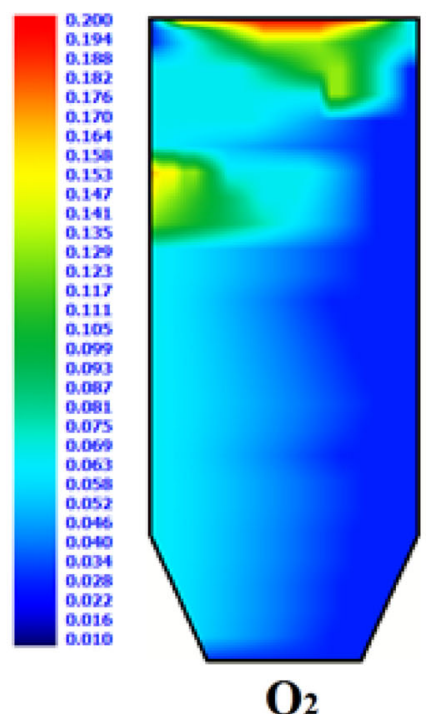

Fig. 4 Contours of the simulated temperature and gas composition distributions along fuel bed reactor 


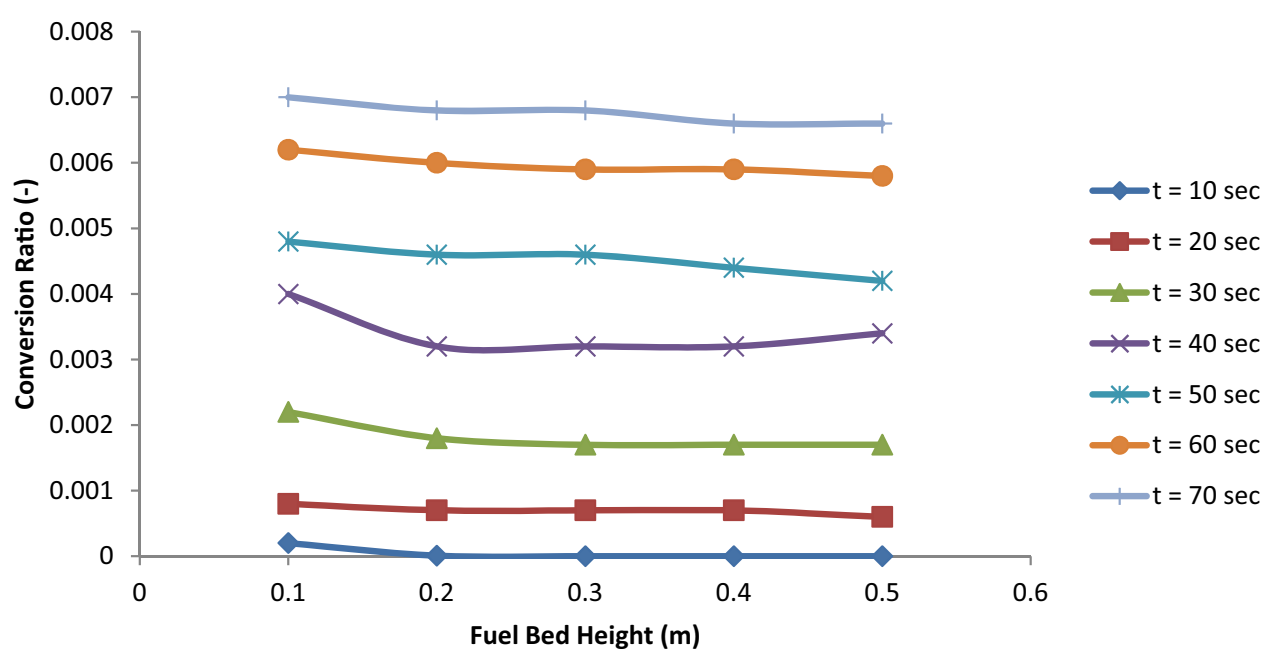

Fig. 5 The $\mathrm{CuO}$ conversion as a function of time at different bed heights

The numerical model, coupled with gas-solid flow with chemical reactions, was developed to simulate the combustion of solids in the CLC. The gas and the particle phases were modeled using the $k-\varepsilon$ turbulent model and the kinetic theory of granular flow. The developed model facilitates the prediction of gas velocities, flow patterns, particle velocities, and composition profiles of gas products and the distribution of heterogeneous reaction rates under typical operating conditions. Furthermore, by comparing the predicted values with the experimental data, the simulations were found to be in good agreement with the experiments. According to the basis of determination coefficient, the value of $\left(R^{2}\right)$ for $\mathrm{CO}, \mathrm{CO}_{2}$ and $\mathrm{CH}_{4}$ was $0.959,0.925$ and 0.969 respectively. This means that the present numerical model is a promising simulation for solid particle combustion.

Open Access This article is licensed under a Creative Commons Attribution 4.0 International License, which permits use, sharing, adaptation, distribution and reproduction in any medium or format, as long as you give appropriate credit to the original author(s) and the source, provide a link to the Creative Commons licence, and indicate if changes were made. The images or other third party material in this article are included in the article's Creative Commons licence, unless indicated otherwise in a credit line to the material. If material is not included in the article's Creative Commons licence and your intended use is not permitted by statutory regulation or exceeds the permitted use, you will need to obtain permission directly from the copyright holder. To view a copy of this licence, visit http://creativecommons. org/licenses/by/4.0/.

\section{References}

Abad A, García-Labiano F, de Diego LF, Gayán P, Adánez J (2007) Reduction kinetics of $\mathrm{Cu}-, \mathrm{Ni}-$, and $\mathrm{Fe}$-based oxygen carriers using syngas $\left(\mathrm{CO}+\mathrm{H}_{2}\right)$ for chemical-looping combustion. Energy Fuels 21:1843-1853
Abanades JC, Diego ME, Fernández JR (2020) A novel air reactor concept for chemical looping combustion systems operated at high pressure. Chem Eng J 390:124507

Adanez J, Garcia-Labiano F, de Diego LF, Gayán P, Abad A, Celaya J (2005) Development of oxygen carriers for chemical-looping combustion. In: Carbon dioxide capture for storage in deep geologic formations-results from the $\mathrm{CO}_{2}$ capture project, vol 1 , pp 587-604

Chen XZ, Shi DP, Gao X, Luo ZH (2011) A fundamental CFD study of the gas-solid flow field in fluidized bed polymerization reactors. Powder Technol 205:276-288

Deng ZY, Xiao R, Jin BS, Song QL (2009) Numerical simulation of chemical looping combustion process with $\mathrm{CaSO}_{4}$ oxygen carrier. Int J Greenhouse Gas Control 3(4):368-375

Dennis JS, Scott SA, Hayhurst AN (2006) In situ gasification of coal using steam with chemical looping: a technique for isolating $\mathrm{CO}_{2}$ from burning a solid fuel. J Energy Inst 79(3):187-190

Gallucci K, Stendardo S, Foscolo PU (2008) $\mathrm{CO}_{2}$ capture by means of dolomite in hydrogen production from syngas. Int $\mathrm{J}$ Hydrogen Energy 33:3049-3055

Hamidouche Z, Masi E, Fede P, Simonin O, Mayer K, Penthor S (2019) Unsteady three-dimensional theoretical model and numerical simulation of a $120-\mathrm{kW}$ chemical looping combustion pilot plant. Chem Eng Sci 193:102-119

Han L, Bollas GM (2016) Dynamic optimization of fixed bed chemical-looping combustion processes. Energy 112:1107-1119

Haus J, Hartge E-U, Heinrich S, Werther J (2018) Dynamic flowsheet simulation for chemical looping combustion of methane. Int $\mathrm{J}$ Greenhouse Gas Control 72:26-37

Holman JP (1994) Experimental method for engineers, 6th edn. McGraw-Hill, Singapore

Hossain MM, de Lasa HI (2008) Chemical-looping combustion (CLC) for inherent $\mathrm{CO}_{2}$ separations-a review. Chem Eng Sci 63:4433-4451

Hoteit A, Forret A, Pelletant W, Roesler J, Gauthier T (2011) Chemical-looping combustion with different types of liquid fuels. Oil Gas Sci Technol Rev. IFP Energies nouvelles 66:193-199

Ismail TM, Ramzy K, Abelwhab MN, Elnaghi BE, Abd El-Salam M, Ismail MI (2018) Performance of hybrid compression ignition engine using hydroxy (HHO) from dry cell. Energy Convers Manag 155:287-300 
Johansson M, Mattisson T, Lyngfelt A (2004) Investigation of $\mathrm{Fe}_{2} \mathrm{O}_{3}$ with $\mathrm{MgAl}_{2} \mathrm{O}_{4}$ for chemical-looping combustion. Ind Eng Chem 43:6978-6987

Jung J, Gamwo IK (2008) Multiphase CFD-based models for chemical looping combustion process: fuel reactor modeling. Powder Technol 183:401-409

Kolbitsch P, Pröll T, Hofbauer H (2009) Modeling of a $120 \mathrm{~kW}$ chemical looping combustion reactor system using a Ni-based oxygen carrier. Chem Eng Sci 64:99-108

Kronberger B, Lyngfelt A, Löffler G, Hofbauer H (2005) Design and fluid dynamic analysis of a bench-scale combustion system with 2 separation-chemical-looping combustion. Ind Eng Chem Res 44:546-556

Leion H, Mattisson T, Lyngfelt A (2007) The use of petroleum coke as fuel in chemical-looping combustion. Fuel 86(12-13):1947-1958

Linderholm C, Schmitz M, Biermann M, Hanning M, Lyngfelt A (2017) Chemical-looping combustion of solid fuel in a $100 \mathrm{~kW}$ unit using sintered manganese ore as oxygen carrier. Int $\mathrm{J}$ Greenhouse Gas Control 65:170-181

Lu H, Gidaspow D, Bouillard J, Wentie L (2003) Hydrodynamic simulation of gas-solid flow in a riser using kinetic theory of granular flow. Chem Eng J 95:1-13

Lyngfelt A (2011) Oxygen carriers for chemical looping combustion $4000 \mathrm{~h}$ of operational experience. Oil Gas Sci Technol - Rev. IFP Energies nouvelles 66:161-172

Lyngfelt A, Leckner B, Mattisson T (2001) A fluidized-bed combustion process with inherent $\mathrm{CO}_{2}$ separation; application of chemical looping combustion. Chem Eng Sci 56:3101-3113

Ma J, Tian X, Wang C, Chen X, Zhao H (2018) Performance of a 50 $\mathrm{kW}$ th coal-fuelled chemical looping combustor. Int J Greenhouse Gas Control 75:98-106

Markström P, Linderholm C, Lyngfelt A (2014) Operation of a $100 \mathrm{~kW}$ chemical-looping combustor with Mexican petroleum coke and Cerrejón coal. Appl Energy 113:1830-1835
Mattisson T, Johansson M, Lyngfelt A (2004) Multicycle reduction. Oxidation of different types of iron oxide particles-application to chemical-looping combustion. Energy Fuels 18(3):628-637

Menon KG, Patnaikuni VS (2017) CFD simulation of fuel reactor for chemical looping combustion of Indian coal. Fuel 203:90-101

Moldenhauer P, Rydén P, Mattisson T, Lyngfelt A (2012) Chemicallooping combustion and chemical-looping with oxygen uncoupling of kerosene with $\mathrm{Mn}$ - and $\mathrm{Cu}$ based oxygen carriers in a circulating fluidized-bed $300 \mathrm{~W}$ laboratory reactor. Fuel Process Technol 104:378-389

Parker JM (2014) CFD model for the simulation of chemical looping combustion. Powder Technol 265:47-53

Patankar SV (1980) Numerical heat transfer and fluid flow. Hemisphere, Washington

Peters B, Thomas N, Christian B (2003) Modelling wood combustion under fixed bed conditions. Fuel 82:729-738

Porrazzo R, White G, Ocone R (2016) Fuel reactor modelling for chemical looping combustion: from micro-scale to macro-scale. Fuel 175:87-98

Scott SA, Dennis JS, Hayhurst AN, Brown T (2006) In situ gasification of a solid fuel and $\mathrm{CO}_{2}$ separation using chemical looping. AIChE J 52(9):3325-3328

Simbeck DR (2004) $\mathrm{CO}_{2}$ capture and storage-the essential bridge to the hydrogen economy. Energy 29:1633-1641

Stendardo S, Foscolo PU (2009) Carbon dioxide capture with dolomite: a model for gas-solid reaction within the grains of a particulate sorbent. Chem Eng Sci 64:2343-2352

Su MZ, Zhao HB, Ma JC (2015) Computational fluid dynamics simulation for chemical looping combustion of coal in a dual circulation fluidized bed. Energy Convers Manag 105:1-12

Wang XF, Jin BS, Zhong WQ (2009) Three-dimensional simulation of fluidized bed coal gasification. Chem Eng Process 48:695-705

Zhang YW, Chao ZX, Hugo AJ (2017) Modelling and simulation of chemical looping combustion process in a double loop circulating fluidized bed reactor. Chem Eng J 320:271-282 